REVISTA DE DERECHO UNED, NÚM. 17, 2015

\title{
ANÁLISIS DE LA SEPARACIÓN CANÓNICA Y CIVIL EN EL SISTEMA MATRIMONIAL ESPAÑOL: REVISIÓN DE LAS NOVEDADES PREVISTAS EN LA LEY DE JURISDICCIÓN VOLUNTARIA Y CONFESIONES DE NOTORIO ARRAIGO
}

\author{
CANONICAL AND LEGAL SEPARATION IN SPANISH \\ MATRIMONIAL SYSTEM: REVISION OF THE VOLUNTARY \\ JURISDICTION LAW AND SOCIAL ROOTED RELIGIOUS \\ CONFESSIONS DEVELOPMENTS
}

\author{
Clara María Arranz Hierro ${ }^{1}$ \\ Máster EEES Familia y Sistemas Hereditarios UNED \\ Doctoranda en Derecho por la USP CEU
}

Resumen: En este artículo haremos, en primer lugar, un acercamiento al sistema matrimonial español, puesto que en nuestro ordenamiento coexisten diversas clases de matrimonio con posibilidad de gozar de efectos civiles. A continuación, abordaremos la institución jurídica de la separación, haciendo un recorrido por su evolución en el Derecho español, habida cuenta de que su trascendencia y efectos jurídicos no han sido idénticos a lo largo de los años. Hemos incluido, adicionalmente, el estudio de las novedades aportadas por la reciente Ley 15/2015, de 2 de julio, de Jurisdicción Voluntaria. Asimismo, incluimos un análisis sobre los presupuestos diferenciadores entre la separación civil y la canónica y trataremos de encuadrar esta última, en la figura de la separación civil de hecho, distinguiéndolas, por último, de la nulidad matrimonial.

\footnotetext{
${ }^{1}$ Agradezco al Departamento de Derecho Civil de la UNED y a su Director, así como a su discípula, la Profesora Moretón Sanz, las apreciaciones, observaciones y revisiones hechas al presente trabajo.
} 
Abstract: In this article we want to do an approach to the Spanish matrimonial system, since they are different types of marriage that could generate civil effects. Afterwards, we will deal with legal separation, doing a journey through its relevance and effects in Spanish law. Is also included the study of the recent 15/2015 legal reform, of Voluntary Jurisdiction. Finally, we differentiate legal from canonical separation, trying to place the latest one in the de facto separation legal form, and those two from legal and canonical marriage annulment.

Palabras clave: Sistemas matrimoniales, separación jurídica, separación canónica, separación de hecho, nulidad.

Keywords: Matrimonial systems, legal separation, canonical separation, 'de facto' separation, marriage annulment.

Recepción original: 15/10/2015

Aceptación original: 30/10/2015

Sumario: I. Sistemas matrimoniales presentes en España: Acuerdos y religiones de notorio arraigo. II. Nociones preliminares acerca de la separación. III. La separación en el Código Civil y sus sucesivas reformas normativas. 1. Regulación hasta la Ley 30/1981: matrimonio único. 2. Regulación desde 1981 hasta 2005: matrimonio civil obligatorio y confesiones religiosas reconocidas. 3. La reforma de la Ley 15/2005: el fin de la separación y el divorcio causalistas. 4. Ley 15/2015, de 2 de julio, de Jurisdicción Voluntaria: matrimonio de las confesiones con notorio arraigo, desjudicialización de la separación. IV. Separación en el Derecho Canónico: Causas tasadas de separatione mantente vinculo. Distinción respecto de la nulidad. V. ¿Es equiparable la separación canónica a la separación civil de hecho? VI. Conclusiones. VII. Bibliografía. VIII. Índice de resoluciones citadas

\section{SISTEMAS MATRIMONIALES PRESENTES EN ESPAÑA: ACUERDOS Y RELIGIONES DE NOTORIO ARRAIGO}

El matrimonio suele ser considerado como institución de derecho natural $^{2}$, que los sistemas jurídicos históricos de todos los países y

${ }^{2}$ Ver, por todos, ARISTÓTELES, Ética a Nicómaco, Mestas, Madrid, 2006, pág. 201: "La amistad entre marido y mujer parece tener su fundamento en la naturaleza, y ello es así porque el hombre, por naturaleza, propende a vivir en pareja antes que en comunidades políticas. Los demás animales se asocian entre sí en la medida en que lo exige la procreación; el hombre y la mujer cohabitan no sólo por la procreación, sino por los demás fines de la vida». 
religiones se han limitado a recoger y proteger $^{3}$, y no a juridificar ex novo. Por tanto, su fundamento no reside en la voluntad del legislador, sino en la propia naturaleza humana. Es, por eso mismo, una institución peculiar, que no puede fácilmente subsumirse en categoría jurídica ordinaria, toda vez que stricto sensu -pese a sus semejanzas-, no termina de concordar con la estructura y finalidad de otras figuras e instituciones próximas.

En cuanto a su definición, el matrimonio no es exactamente un contrato (aunque tenga muchas de sus notas características), sino un negocio jurídico especial ${ }^{4}$-como ha convenido en denominarlo la doctrina mayoritaria, después de siglos de controversia-, formado por la concorde voluntad de los contrayentes de unirse conyugalmente.

Si hablamos de matrimonio en España, es menester hacer una aclaración: en nuestro país no existe un solo tipo de matrimonio, sino todo un sistema matrimonial, entendiendo por éste, según SATORRAS FIORETTI, el «modo jurídico de regular la coexistencia, en un país y en un momento histórico dado, de dos o más instituciones matrimoniales correspondientes a otros tantos ordenamientos jurídicos» ${ }^{5}$.

Por otra parte, existe en el Derecho Comparado una amplia tipología de sistemas matrimoniales, entre los cuales destacamos tres: el sistema de matrimonio religioso obligatorio (en el cual el matrimonio debe celebrarse conforme a la religión oficial del Estado, como ocurre actualmente en algunos países islámicos), el sistema de matrimonio civil obligatorio (en el que el matrimonio debe contraerse según el derecho civil, si bien se permite una segunda celebración en la forma o rito religioso que se quiera), y el sistema facultativo (en sus vertientes anglosajona y latina, según si hablamos de un único matrimonio civil con pluralidad de formas o bien de dos clases de matrimonio, a

${ }^{3}$ El hecho de que el matrimonio exista previamente a su regulación jurídica, como institución natural, no obsta para que el Derecho vele por su integridad, en cuanto que pilar inmediato de la familia y mediato de la sociedad en general. De la misma opinión es PERALES AGUSTÍ, M. en «Los impedimentos matrimoniales», en VV. AA. Coord. por JUSDADO, M. Derecho Matrimonial Canónico y Eclesiástico del Estado, 2. ${ }^{\text {a }}$ ed., Colex, Madrid, 2007, pág. 66, si bien hace referencia desde la óptica de los impedimentos para contraer.

${ }^{4}$ Sobre la cuestión de la naturaleza jurídica del matrimonio, ver SATORRAS FIORETTI, R. M. «Los matrimonios religiosos con eficacia civil», en VV. AA. Coord. por VILLAGRASA ALCAIDE, C. Derecho de Familia, Bosch, Barcelona, 2011, pág. 59, así como LASARTE ÁlVAREZ, C. Derecho de Familia. Principios de Derecho Civil VI, Marcial Pons, Madrid, 2010, págs. 26 y ss.

${ }^{5}$ SATORRAS FIORETTI, Op. cit., pág. 53. 
elegir: civil y religioso, estando este último reconocido en el ordenamiento civil).

Podemos afirmar que el sistema vigente en España es mixto, plenamente facultativo ${ }^{6}$ y pluralista, en el que «conviven junto al matrimonio civil un matrimonio religioso reconocido institucionalmente -esto es, regido en sus aspectos sustantivos por su normativa confesional- y otros matrimonios formalmente religiosos, aunque regulados en sus requisitos de fondo por el Derecho Civil» ${ }^{7}$.

A este sistema hemos llegado tras una larga evolución ${ }^{8}$ en la que, de partida -desde la Edad Media y hasta 1870- solo se reconocía como matrimonio el canónico, pasando luego por diversas etapas de alternancia entre el sistema de matrimonio civil obligatorio (1870-75 y 1932-38), y el de de matrimonio civil subsidiario, que ha permanecido vigente hasta la promulgación de la Constitución Española de 1978.

El Estado español, en el momento de redactar estas líneas, tiene firmados acuerdos en materia matrimonial:

- Con la Iglesia Católica, Acuerdo con la Santa Sede sobre Asuntos Jurídicos (AAJ) ${ }^{9}$, de 3 de enero de 1979, ratificado el 4 de diciembre de 1979;

${ }^{6}$ Desde el Decreto de 9 de febrero de 1875, contábamos en nuestro país con un sistema de matrimonio civil subsidiario. Ahora, en cambio, el modelo es el de matrimonio civil facultativo. Haciendo un breve recorrido histórico, afirma FERRER ORTIZ, J. «La eficacia civil del matrimonio canónico y de las decisiones eclesiásticas en el Derecho español», Ius et Praxis, 14, 2, 2008, pág. 376, que «a lo largo de casi un siglo (1875-1981) el sistema matrimonial español estará centrado en el binomio matrimonio civil-matrimonio canónico; con la peculiaridad de que en todo ese tiempo las sucesivas redacciones del Código civil, exceptuada la etapa republicana (19321938), reconocen el matrimonio canónico como una realidad con sustantividad propia». También habla del sistema matrimonial español como «electivo y facultativo» LASARTE ÁLVAREZ, en $O p$. cit., pág. 34.

${ }^{7}$ CAÑAMARES ARRIBAS, S. «El sistema matrimonial español», en VV. AA., Coord. por JUSDADO RUIZ-CAPILLAS, M. A. Derecho Matrimonial Canónico y Eclesiástico del Estado, Colex, Madrid, 2007, pág. 257. No olvidemos la reforma llevada a cabo por la Ley 15/2015, de Jurisdicción Voluntaria, que tiene también en cuenta las confesiones religiosas con notorio arraigo en España, como más adelante veremos.

${ }^{8} \mathrm{Vid}$. SANCHO REBULLIDA, F. «El matrimonio canónico en el sistema matrimonial español», Ius Canonicum, 20, 40, 1980, págs. 15 y 16.

${ }^{9}$ Nos parece muy interesante la reflexión de FERRER ORTIZ, en Op. cit., pág. 383, en la que expone una visión del Derecho Civil sobre la regulación matrimonial canónica en tres momentos diferenciados: «El Acuerdo sobre asuntos jurídicos dedica al matrimonio canónico el artículo 6 y el Protocolo final. El sistema en ellos delineado marca un hito en el Derecho matrimonial español y en el Derecho concordatario, porque supone la implantación de un nuevo modelo facultativo con tres momentos y distintas normas gravitando sobre cada uno de ellos. En el momento 
Análisis de la separación CANÓNica y Civil en el Sistema...

- Con la Federación de Entidades Religiosas Evangélicas de España, Ley 24/1992, de 10 de noviembre;

- Con la Federación de Comunidades Judías de España, Ley 25/1992, de 10 de noviembre;

- Con la Comisión Islámica de España, Ley 26/1992, de 10 de noviembre.

Debido al creciente pluralismo religioso de nuestro país, el Proyecto de Ley de Jurisdicción Voluntaria de 1 de agosto de $2014^{10}$ planteó, entre otras novedades, la posibilidad de dotar también de eficacia civil a los ritos religiosos matrimoniales de mormones, ortodoxos, testigos de Jehová y budistas. Estas confesiones, que hasta ahora carecían de acuerdos con el Estado, requerían de sus fieles el contraer, además, vía civil para que su matrimonio tuviera validez en España. El antedicho proyecto fue aprobado como Ley 15/2105, de 2 de julio, de Jurisdicción Voluntaria, y supone el más reciente cambio en el panorama jurídico matrimonial español, ampliándose el sistema matrimonial a todas las religiones de notorio arraigo, como veremos en el apartado específicamente dedicado a esta reforma legislativa.

La pluralidad y libertad de elección vienen impuestas, como es lógico, por el propio corpus Constitucional, en sus artículos 32.1, 16.2, 16.3 y $14^{11}$. Gracias a esta facultad de elección, en España se puede contraer matrimonio civil -en forma civil o religiosa- o canónico, y ambos tendrán efectos civiles ${ }^{12}$, con las salvedades que más adelante analizaremos.

constitutivo el Estado contempla el matrimonio canónico como realidad autónoma que produce los mismos efectos que el matrimonio civil y reconoce a los ciudadanos la facultad de elegir libremente entre una u otra forma de celebración. En el momento registral el Estado supedita el pleno reconocimiento de los efectos civiles del matrimonio canónico a la inscripción en el Registro civil para evitar que los matrimonios canónicos contrarios a su orden público alcancen eficacia civil. En el momento procesal los cónyuges pueden optar por la jurisdicción eclesiástica o por la jurisdicción civil para obtener la disolución o la declaración de nulidad del matrimonio canónico, pero las decisiones eclesiásticas solo tendrán efectos civiles si se declaran ajustadas al Derecho del Estado».

${ }^{10} \mathrm{Vid}$. N. ${ }^{\circ} 11$ de la Disposición Final Primera del Proyecto de Ley.

${ }^{11}$ BERCOVITZ RODRÍGUEZ-CANO, R. «La ejecución de las sentencias eclesiásticas de separación matrimonial por la jurisdicción civil después de la Constitución: comentario a la STC de 26 de enero de 1981», Revista española de Derecho Constitucional, 1, 3, 1981, pág. 153.

${ }^{12}$ En el artículo 6.1 del Acuerdo sobre Asuntos Jurídicos «el Estado reconoce los efectos civiles al matrimonio celebrado según las normas del Derecho Canónico» y precisa que «se producen desde su celebración». 


\section{NOCIONES PRELIMINARES ACERCA DE LA SEPARACIÓN}

Podemos definir la separación como la institución jurídica que comporta la suspensión de la vida en común de los cónyuges permaneciendo incólume el vínculo matrimonial, y pudiendo ser rehabilitada la unión mediante el instrumento jurídico de la reconciliación ${ }^{13}$. Por el contrario, sabido es que el divorcio sí conlleva una disolución del vínculo, al menos en sede civil ${ }^{14}$. Es por esto que, a veces, se ha denominado a la separación con la terminología de «divorcio no vincular».

Para que podamos hablar de verdadera separación se requiere la existencia de un animus específico,-animus desirendi- que la distingue de un simple alejamiento físico.

Debido a la subsistencia del vínculo, aunque los cónyuges se encuentren separados se mantiene vigente para ambos el impedimento de contraer nuevo matrimonio ${ }^{15}$. No obstante, tal y como señala DÍEZ-PICAZO ${ }^{16}$, el régimen jurídico de derechos y obligaciones de los cónyuges experimenta una transformación.

Dado que existen ciertas diferencias entre las regulaciones civil y canónica de la separación, y puesto que ambas se admiten en nuestro ordenamiento jurídico, las estudiaremos de forma individualizada.

\section{LA SEPARACIÓN EN EL CÓDIGO CIVIL Y SUS SUCESIVAS REFORMAS NORMATIVAS}

La separación aparece regulada de forma autónoma en los artículos 81 a 84 del CC. Esta regulación ha variado notablemente en los

${ }^{13}$ LÓPEZ-MÚÑIZ CRIADO, C. "Separación», en VV. AA. Coord. por O'CALLAGHAN, X. Matrimonio: nulidad canónica y civil, separación y divorcio, Editorial Centro de Estudios Ramón Areces, Madrid, 2007, pág. 183. Ver también el recientemente modificado artículo $84 \mathrm{CC}$.

${ }^{14}$ No así en el Derecho Canónico, donde se afirma la indisolubilidad del vínculo matrimonial creado conforme a derecho. Vid. Canon 1056 CIC (Corpus Iuris Canonici).

${ }^{15}$ Cfr. GARCÍA GÁRATE, A. El matrimonio canónico en su dimensión sustantiva y procesal, Dykinson, Madrid, 2007, pág. 34. Este autor señala que el fundamento del impedimento de vínculo o ligamen previo es, claramente, la monogamia del sistema matrimonial español, siguiendo nuestra milenaria tradición occidental. Aparecía regulado en el ordenamiento civil (art. 46.2 CC) y en el canónico (Canon 1085 CIC). De hecho, atentar contra este vínculo contrayendo un segundo matrimonio sin que el primero se haya disuelto constituye actualmente un ilícito penal, regulado en el artículo $217 \mathrm{CP}$.

${ }^{16}$ DÍEZ-PICAZO, L. y GULLÓN, A. Sistema de Derecho Civil. Derecho de Familia. Derecho de Sucesiones, Vol. IV, Tecnos, Madrid, 2008, pág. 98. 
últimos años, fruto de las reformas operadas por la Ley 7/1981 de 7 de julio, -por la que se modifica la regulación del matrimonio en el Código Civil-y la Ley 15/2005 de 8 de julio, -por la que se modifican el Código Civil y la Ley de Enjuiciamiento Civil en materia de separación y divorcio-. Por último, con la entrada en vigor de la Ley 15/2015 de Jurisdicción Voluntaria, de 2 de julio, el panorama matrimonial español se ha visto nuevamente modificado.

\section{Regulación hasta la Ley 30/1981: Matrimonio único}

Recordemos que, hasta esa fecha, la separación era la única forma de cese de la convivencia conyugal, puesto que el divorcio no se admitía jurídicamente en España. El único matrimonio reconocido en España era el canónico, puesto que el Estado se declaraba confesional católico. Fue en la Ley 30/1981, de 7 de julio, cuando se instaura el divorcio en nuestro ordenamiento.

En cuanto a su consideración social y legal, la separación se entendía más como una «sanción civil por hechos antijurídicos y tipificados legalmente ${ }^{17}$ que como un remedio jurídico ${ }^{18}$. Se distinguía en la ley entre el cónyuge culpable, que había infringido una o varias de sus obligaciones conyugales, y el cónyuge inocente, único legitimado para instar la separación, atribuyendo para cada uno diversas consecuencias jurídicas.

Podía acudirse a la separación siempre que concurrieran unas causas tasadas, a saber:

- Abandono injustificado del hogar, infidelidad conyugal, conducta injuriosa o vejatoria y cualquier otra violación grave o reiterada de los deberes conyugales del artículo $68 \mathrm{CC}$.

- Violaciones graves y reiteradas de los deberes respecto de los hijos.

- Condena privativa de libertad por tiempo superior a 6 años.

${ }^{17}$ DÍEZ-PICAZO y GULLÓN, Op. cit., pág. 98.

${ }_{18}$ Aunque por vía jurisprudencial se iba matizando este concepto. Señala LÓPEZMÚÑIZ CRIADO, en Op. cit., pág. 182, que «la sentencia de 25 de abril de 1994 de la Audiencia Provincial de Palencia entiende la finalidad de la separación como un remedio para evitar una convivencia forzada que, a largo plazo, repercutiría en la estabilidad psicológica de cónyuges e hijos». 
- Alcoholismo, toxicomanía o perturbaciones mentales, cuando el interés del otro cónyuge o de los hijos exijan la suspensión de la convivencia.

- Cese efectivo de la convivencia conyugal durante 6 meses.

- Cualquiera de las causas de divorcio del artículo 86 CC.

\section{Regulación desde 1981 hasta 2005: Matrimonio civil obligatorio y confesiones religiosas reconocidas}

A partir de la reforma del Código Civil operada por la Ley 30/1981, de 7 de julio, podían tener efectos civiles en nuestro ordenamiento no solo el matrimonio civil, sino también -cumpliendo las condiciones señaladas por el artículo 60 CC- los celebrados según las confesiones reconocidas en los acuerdos con el Estado: judía, islámica y protestante.

Esta reforma de 1981, que introdujo el divorcio en España, dotó a la separación de configuración autónoma como solución específica y diferenciada de las crisis matrimoniales, caracterizada por la transitoriedad. En consecuencia, en palabras del Profesor LASARTE ÁLVAREZ, «la separación, sea legal o de hecho, constituye por lo común una situación relativamente pasajera y transitoria, con la vista puesta en la eventual reconciliación de los cónyuges o, por el contrario, en la desembocadura del divorcio» ${ }^{19}$.

Además, con la promulgación de esta Ley desapareció la consideración explícita de culpabilidad de uno de los cónyuges, pasando a un sistema de causas objetivas de separación, si bien, como afirma ROMERO COLOMA, «hay que admitir que siguen manteniéndose causales de contenido culpabilístico o de cierto reproche ${ }^{20}$. La autora pone como ejemplo el caso de la esquizofrenia, desde el momento en que uno de los cónyuges, el que no está afectado por la enfermedad, es quien estaba legitimado para instar la separación alegando dicha enfermedad, en aras del bien de la familia.

Esta fue precisamente una de las razones que motivaron la reforma legal de 2005, si bien la doctrina no es unánime al respecto, e incluso encontramos algún pronunciamiento jurisprudencial que seña-

${ }^{19}$ LASARTE ÁLVAREZ, Op. cit., pág. 88.

${ }^{20}$ ROMERO COLOMA, A. M. «La esquizofrenia como causa de separación matrimonial en el Ordenamiento Jurídico Civil español», Revista Crítica de Derecho Inmobiliario, 76, 658, 2000, págs. 1477 y 1484. 
la las bondades de regulación de 1981. Veamos, por ejemplo, la STS de 3 de enero de 1983, que afirmaba que «la actual redacción del CC se orienta en el sentido de regular la crisis matrimonial que da lugar a la separación o al divorcio atendiendo a (...) lo menos malo para los hijos y los propios cónyuges, huyendo de reproches y castigos que conducen a consecuencias frecuentemente absurdas y negativas para los propios implicados, además de injustas por limitar el análisis de la ruptura de la convivencia a ciertos hechos externos reprobables».

\section{La reforma de la Ley 15/2005: El fin de la separación y el divorcio causalistas}

Para comprender la ratio legis de esta reforma en sede matrimonial, creemos conveniente citar un párrafo de la Exposición de Motivos:

«Se estima que el respeto al libre desarrollo de la personalidad, garantizado por el artículo 10.1 de la Constitución, justifica reconocer mayor trascendencia a la voluntad de la persona cuando ya no desea seguir vinculado con su cónyuge. Así, el ejercicio de su derecho a no continuar casado no puede hacerse depender de la demostración de la concurrencia de causa alguna, pues la causa determinante no es más que el fin de esa voluntad expresada en su solicitud, ni, desde luego, de una previa e ineludible situación de separación. (...) Se mantiene la separación judicial como figura autónoma, para aquellos casos en los que los cónyuges, por las razones que les asistan, decidan no optar por la disolución de su matrimonio. En suma, la separación y el divorcio se concibe como dos opciones, a las que las partes pueden acudir para solucionar las vicisitudes de su vida en común ${ }^{21}$.

Vemos que la concepción causal de la separación se ha eliminado por completo tras esta reforma legal, permitiéndose que la separación judicial sea solicitada incluso por uno solo de los cónyuges, ya que lo único que la Ley requiere es el cese de la affectio maritalis, o voluntad de ambos cónyuges de seguir constituyendo un matrimonio tal y como el derecho lo concibe.

Atendiendo a la regulación de 2005 en la materia, constatamos que en España existen dos tipos de separaciones civiles:

- La separación judicial, a solicitud de uno de los cónyuges (contenciosa) o de los dos (de mutuo acuerdo).

${ }^{21}$ Exposición de Motivos de la Ley 15/2005 de 8 de julio, por la que se modifican el Código Civil y la Ley de Enjuiciamiento Civil en materia de separación y divorcio. 
- La separación de hecho (situación fáctica), -opción reconocida por la jurisprudencia desde finales del S. $\mathrm{XX}^{22}-$, que puede ser incluso acordada convencionalmente por ambos cónyuges, o por uno de ellos, incluso contra el criterio del otro.

En este artículo ahondaremos más en la segunda, puesto que es la que presenta más dudas en cuanto a su regulación y efectos jurídicos.

\section{Ley 15/2015 de jurisdicción voluntaria: Matrimonio de las confesiones con notorio arraigo, desjudicialización de la separación}

Recientemente ha sido aprobada la Ley 15/2015, de 2 de julio, de Jurisdicción Voluntaria (LJV). Esta reforma responde a las necesidades -evidenciada por la doctrina desde hace años-, relativas a una mayor coherencia sistemática del Derecho Procesal español. Gracias a la promulgación de esta ley, la Jurisdicción voluntaria ha sido desgajada de la Ley de Enjuiciamiento Civil (LEC), y se regula ahora de forma autónoma.

La LJV postula, en cuanto al proceso, que ciertas cuestiones de jurisdicción voluntaria sean encomendadas a órganos públicos -Secretarios judiciales, Notarios, Registradores- diferentes de aquellos que detentan el poder de juzgar y hacer ejecutar lo juzgado ${ }^{23}$, "por razones de oportunidad política o de utilidad práctica» ${ }^{24}$, siempre y cuando no se trate de derechos fundamentales ni se encuentren afectados los intereses de menores o personas necesitadas de especial protección.

Dentro del ámbito de la jurisdicción voluntaria se encuentran, por supuesto, ciertas cuestiones relativas al matrimonio, concretamente tres:

- Los requisitos que han de concurrir para contraer matrimonio con efectos civiles en nuestro ordenamiento. Se regula, en este sentido, la obligación de formalizar un expediente matrimonial previo, encomendado al Secretario Judicial, Notario,

${ }^{22}$ Como ejemplo citamos la STS de 25 de noviembre de 1985, que afirma en cuanto a su licitud: «La obligación de convivencia que el artículo 68 impone a los cónyuges, reflejada en la tradicional expresión de unidad de techo, mesa y lecho (thorum, mensa et cohabitatio), no impide el hecho, harto frecuente, de que no obstante su nota esencial en el matrimonio, es infringida por pacto, expreso o tácito, de marido y mujer».

${ }^{23}$ Ex. artículo 117 Constitución Española, entendido stricto sensu.

${ }^{24}$ Ver el Preámbulo de la Ley 15/2015, n. ${ }^{\circ}$ IV. 
encargado del Registro Civil o funcionario en Registro Civil extranjero.

- Los requisitos exigibles a la hora de celebrarse el matrimonio. Esta podrá tener lugar ante el Secretario judicial, Notario, funcionario diplomático o consular, Juez de Paz y Alcalde o concejal en el que este delegue.

- La regulación de la separación y el divorcio de mutuo acuerdo, siempre que se trate de cónyuges sin hijos menores. Esta cuestión se ha desjudicializado, dado que la LJV atribuye ahora al Secretario Judicial y al Notario las funciones que hasta ahora correspondían al Juez ${ }^{25}$.

De este modo, resultan modificados por la Disposición Transitoria 5. ${ }^{a}$ los Acuerdos de Cooperación del Estado español con las comunidades religiosas judía ${ }^{26}$, islámica ${ }^{27}$ y evangélica ${ }^{28}$. La ratio legis, en este sentido, ha sido equiparar el derecho a celebrar matrimonio religioso con efectos civiles de las religiones con acuerdos suscritos, a aquellas que, en atención al pluralismo religioso de nuestro país, son reconocidas como religión de notorio arraigo.

La entrada en vigor de estas disposiciones de la Ley 15/2015 relativas al matrimonio será, a tenor de la Disposición Final 21. ${ }^{\mathrm{a}}$, el 30 de junio de 2017.

\section{SEPARACIÓN EN EL DERECHO CANÓNICO: CAUSAS TASADAS DE SEPARATIONE MANTENTE VINCULO. DISTINCIÓN RESPECTO DE LA NULIDAD}

En el ámbito del Derecho Matrimonial Canónico, de cuya aplicabilidad en España ya hemos hablado anteriormente, la principal fuente reguladora es el Código de Derecho Canónico $\left(\mathrm{CIC}^{29}\right)$, cuya última reforma data de 1983. En concreto, los cánones que tratan la separación son los siguientes: 1151 a 1155 (en cuanto al Derecho sustantivo) y 1692 a 1696 (en lo referente al proceso). Algunos de los artículos referentes a los procesos matrimoniales canónicos se han visto recientemente reformados por la disposición del Papa Francisco Mites Iudex Dominus Iesus, de 2 de septiembre de 2015.

${ }^{25}$ Ver el Preámbulo de la Ley 15/2015, n. ${ }^{\circ}$ XI.

${ }^{26}$ Ley 25/1992, de 10 de noviembre.

${ }^{27}$ Ley 26/1992, de 10 de noviembre.

${ }^{28}$ Ley 24/1992, de 10 de noviembre.

${ }^{29}$ Corpus Iuris Canonici o Código de Derecho Canónico, 1983. 
A tenor de estos cánones, se habla de separatione mantente vinculo como posibilidad de que se suspenda temporalmente el deber de mantenimiento de la convivencia conyugal ${ }^{30}$. Por lo tanto, se contempla como una situación excepcional, en la cual no obstante permanece inalterado el vínculo conyugal ${ }^{31}$, por lo que, stricto sensu, no podemos decir que sea una especie de estado intermedio entre la plena validez del matrimonio y su disolución. Utilizando a terminología aristotélica, estaríamos ante un cambio accidental del estado matrimonial.

En cuanto al origen de la institución jurídica de la separación conyugal, estamos de acuerdo con LORENZO CRUZ cuando afirma que su aparición se debió al cristianismo ${ }^{32}$. Solo partiendo de la indisolubilidad $^{33}$ del matrimonio, se entiende la existencia de la separación como remedio jurídico de las crisis matrimoniales, en el cual el vínculo permanece vigente. La regulación del Derecho Canónico influyó, tanto en materia de separación como en muchas otras -si bien no es

${ }^{30}$ El Canon 1151 establece literalmente. "Los cónyuges tienen el deber y el derecho de mantener la convivencia conyugal a no ser que les excuse una causa legítima».

${ }^{31}$ ESCRIVÁ-IVARS, J. «Separación conyugal y mediación», Ius Canonicum, 61, 81,2001 , pág. 259 , afirma que el vínculo «pervive con la misma fuerza que en todas las formas posibles de normalidad matrimonial». De la misma opinión es PEÑA GARCÍA, C. El matrimonio. Derecho y praxis de la Iglesia, Universidad Pontificia Comillas, Bilbao, 2004, pág. 58, quien afirma: «La separación no afecta al vínculo conyugal, que permanece, sino únicamente a la vigencia de los derechos y obligaciones conyugales (y, en especial, a la obligación de los cónyuges de convivir), que quedan en suspenso".

${ }^{32}$ LORENZO CRUZ, A. «La separación matrimonial de hecho», Anuario de la Facultad de Derecho, n. ${ }^{\circ}$ 3, 1984-1985, págs. 508 y 509.

${ }^{33}$ Desde el Derecho Romano, las diferencias entre el matrimonio pagano y el cristiano fueron fundamentalmente dos: el consentimiento, -que en sede cristiana era jurídicamente considerado como inicial y no mantenido en forma de una voluble affectio maritalis - y la indisolubilidad, derivada tanto de la naturaleza sacramental del matrimonio (TEJERO, E. «La sacramentalidad del matrimonio en la historia del pensamiento cristiano», Ius Canonicum, 14, 27, 1974, pág. 28) como de diversos pasajes bíblicos (Gn. 2, 24; Mt, 5, 27; Lc, 16, 18; 1. ${ }^{a}$ Cor. 7, 1-39...). De la misma opinión es MARTÍNEZ SAGASTI, A. M. «Procedimientos jurídicos para la separación conyugal», Ius Canonicum, 17, 34, 1977, pág. 109, quien afirma que «la separación conyugal, entendida como separación sin disolución del vínculo, es una figura típica del Derecho Canónico, que surge y se va delimitando al aplicar al matrimonio la doctrina, recogida en el Nuevo Testamento, sobre la indisolubilidad de todo matrimonio contraido válidamente». Otros autores ven en la doctrina cristiana de la indisolubilidad una recuperación del Derecho Natural (vid. D'ORS, A. Derecho Privado Romano, Eunsa, Pamplona, 1991, pág. 288). En nuestra opinión, sólo desde la consideración de la indisolubilidad del vínculo conyugal se entienden los remedios jurídicos que respetan su integridad, aunque la convivencia de los cónyuges se vea interrumpida por diversas razones. 
este el lugar propicio para analizarlas-, en los ordenamientos civiles de los Estados Modernos.

Actualmente encontramos que la regulación canónica contempla varios tipos de separación. Si atendemos a su fuente normativa, ratificamos que el ordenamiento distingue entre separación legal y separación de hecho ${ }^{34}$. Esta última puede ser tanto unilateral como convencional $^{35}$. Si nos detenemos, en cambio, en el factor temporal, la mayor parte de los casos será una situación transitoria, lo cual es acorde a la propia naturaleza de la separación, mientras que solo en caso de adulterio ${ }^{36}$ podremos hablar, excepcionalmente, de una separación canónica perpetua. Por último, clasificándolas según el procedimiento a través del cual se sustancie, podemos hablar de separación administrativa $^{37}$ o judicial ${ }^{38}$. No es aventurado afirmar que el CIC prefiere, con mucho, la solución extrajudicial de los conflictos matrimoniales.

En este proceso canónico administrativo tiene competencia objetiva el Obispo diocesano (ex. Canon 1692.1 CIC) o aquellos en quienes él delegue a través del otorgamiento de un mandato especial (137 CIC). La competencia territorial está determinada por el lugar del

${ }^{34}$ LÓPEZ-ALARCÓN, M. y NAVARRO-VALLS, R., afirman, en Curso de Derecho Matrimonial Canónico y Concordado, Tecnos, Madrid, 2010, pág. 392, que «no se puede asegurar (...) que la Iglesia consiente la separación de hecho de modo general e indiscriminado, sino por justas causas, que son, precisamente, las mismas que se establecen para la separación de derecho por vía administrativa o judicial, considerándose ilícitas las separaciones sin causa, arbitrarias y por causa torpe. (...) Lo que hace el CIC es reconocer la legitimidad de la constitución unilateral del estado de separación de hecho en los restringidos supuestos previstos por los cánones 1152 y 1153, relegando a la jurisdicción civil la regulación del régimen jurídico del estado de separación de hecho».

${ }^{35}$ Interpretando a fortiori el Canon 1153, que admite la separación por voluntad de uno de los cónyuges, siempre y cuando concurran determinadas circunstancias, LÓPEZ-ALARCÓN y NAVARRO-VALLS, defienden en Op. cit., pág. 393, que la separación amistosa, recogida en pacto tácito o expreso, preferiblemente recogido en escritura pública o privada, es admisible en el ordenamiento canónico.

${ }^{36}$ El Canon 1152 establece que el cónyuge no adúltero tiene derecho a romper la convivencia conyugal, salvo que hubiera consentido el adulterio o lo hubiera cometido también él (o ella, pues este canon se aplica por igual a varones y mujeres).

${ }^{37}$ La separación administrativa es aquella que se tramita ante el Obispo Diocesano, según las disposiciones del Canon 1692. Ofrece, frente a la vía canónica judicial, las ventajas de una mayor rapidez y un menos coste económico. La elección del proceso a seguir corresponde, en principio, a las partes interesadas, si bien el CIC dispone en ciertos casos la intervención del Promotor de Justicia (vid. Canon 1693.1).

${ }^{38}$ Hablamos de separación judicial cuando la causa es llevada por un Juez o Tribunal Eclesiástico, lo cual suele sustanciarse habitualmente a través de un procedimiento contencioso oral, si bien a instancia de parte puede ser modificado a juicio ordinario o incluso remitido a la vía civil, si se pretende la declaración de determinados efectos, como después veremos. 
domicilio de los cónyuges (104 CIC). La tramitación de este procedimiento de separación es sencilla; citamos a continuación la síntesis que de la misma hace SATORRAS FIORETTI ${ }^{39}$ :

— «Solicitud de separación que señale la causa legal y que acompañe la prueba (si es documental) o que la proponga para que el Obispo ordene su práctica.

- Citación de los cónyuges para procurar la reconciliación.

- Nueva citación de los cónyuges y del promotor de justicia para que formulen alegaciones y propongan las pruebas.

- Si alguno solicita el proceso contencioso, se clausura el procedimiento y se envía al Tribunal correspondiente».

En cuanto a las causas de separación «de derecho ${ }^{40}$ que el Derecho Canónico contempla, nos parece interesante señalar, por ser ésta una de las diferencias principales con el Derecho Civil, que el CIC de 1983 solo reconoce las siguientes:

- Adulterio (Canon 1152).

- Grave peligro espiritual o corporal de un cónyuge provocado por el otro cónyuge (Canon 1153).

- Grave peligro de la prole causado por uno de los cónyuges (Canon 1153).

- Que uno de los cónyuges haga demasiado dura la vida en común (Canon 1153).

En otras palabras, se trata de causas que suponen una lesión o un grave incumplimiento de los principios básicos del matrimonio ${ }^{41}$, a saber: la fidelidad de los cónyuges, la mutua convivencia, la ayuda espiritual y material entre ellos o respecto de los hijos... Este incumplimiento es el que legitima al cónyuge que lo sufre a pedir unilateralmente la separación o, de hecho, a ponerla por obra. La Iglesia afirma que estos motivos de separación derivan, precisamente, del derecho

${ }^{39}$ SATORRAS FIORETTI, Op. cit., pág. 95.

40 «La separación de derecho es la que se funda en una causa legítima y es pronunciada por la autoridad eclesiástica en el proceso adecuado, quedando sujetos los esposos y los hijos, si los hubiere, al régimen jurídico especial de matrimonio separado». No olvidemos que esta separación, que canónicamente puede ser «de derecho», no tiene porqué serlo civilmente, a menos que se sustancie también civilmente por la vía judicial. Vid. VV. AA. "El momento crítico de los matrimonios religiosos», en YZQUIERDO TOLSADA, M., y CUENA CASAS, M. Tratado de Derecho de la Familia, Vol. II, Las Crisis Matrimoniales, Thomson Reuters, Pamplona, 2011, pág. 853.

${ }^{41}$ Cánones 1135 y 1136 CIC. 
natural, de la propia naturaleza de la institución matrimonial ${ }^{42}$, y no son fijadas ex novo por el ordenamiento jurídico eclesiástico, lo cual marca sin duda una distancia respecto de la regulación civil que no exige causa alguna para separarse. En cuanto al régimen jurídico del estado de separación canónica de hecho, el CIC se remite al Derecho Civil.

Es conveniente reconocer que, a pesar de su regulación propia en los cánones antedichos, el índice de separaciones canónicas es muy bajo $^{43}$. En parte podemos explicar este fenómeno porque desde el Derecho Canónico -también desde el Civil, qué duda cabe-, se han tratado de promover en los últimos años, además de la separación, medidas menos drásticas de resolución de los conflictos entre los cónyuges, pudiendo éstos optar por recurrir a terapia de pareja, psicoterapia, tratamiento médico psiquiátrico, mediación de familiares $\mathrm{y}$ amigos o de instituciones especializadas... Pero, de forma adicional, entendemos que el brusco descenso del número de separaciones canónicas en España se debe, principalmente, a un aumento de las separaciones y divorcios por vía civil, debido a que, incluso entre católicos practicantes, muchas veces se desea que la separación surta efectos patrimoniales y paternofiliales que la separación canónica per se no es susceptible de generar.

En lo relativo a la evolución histórica de la regulación de la separación canónica matrimonial, podemos hablar de varios hitos ${ }^{44}$. El CIC de 1917, vigente hasta 1983, establecía que «las causas entre bautizados pertenecen por derecho propio y exclusivo al Juez eclesiástico». Por lo tanto, todos los casos de separaciones de católicos eran conocidos por la jurisdicción eclesiástica, y no por la civil.

Con la firma del Concordato de 27 de agosto de $1953^{45}$ se confirmó la competencia exclusiva de los Tribunales eclesiásticos en las causas matrimoniales, incluidas las de separación. Hasta ese momento, las sentencias eclesiásticas gozaban de efectos civiles directos.

Sin embargo, con la promulgación de la Constitución de 1978, que declaró la aconfesionalidad del Estado español, se produjo la secula-

${ }^{42}$ MARTÍNEZ SAGASTI, $O p$. cit., pág. 117.

${ }^{43} \mathrm{Al}$ respecto, vid. LIPKA, en Op. cit., pág. 529, quien da las siguientes cifras de separaciones canónicas en España: en el año 1970, 3195 separaciones; en 1980, 4363; un año después, en 1981, casi la mitad, 2763; en 1982, 921 separaciones; en 1985, 39; en 1988, el escaso número de 20.

${ }^{44}$ Etapas comentadas por LÓPEZ-ALARCÓN y NAVARRO-VALLS, en Op. cit., págs. 394 y 395.

${ }^{45} \mathrm{Vid}$. artículo 24. 
rización de las causas de separación ${ }^{46}$, quedando éstas reservadas a la Ley civil por mandato del artículo 32. CE. Esta reserva fue posteriormente confirmada por el artículo 82 del actual CC. A mayor abundamiento, de la interpretación literal del artículo VI del Acuerdo sobre Asuntos Jurídico ${ }^{47}$ se desprende que las sentencias canónicas de separación conyugal no producirán efectos $\operatorname{civiles}^{48}$, puesto que dicho artículo solo hace alusión a las de nulidad matrimonial y disolución por matrimonio rato no consumado ${ }^{49}$.

En idéntica línea se pronuncia el Real Decreto-ley de 29 de diciembre de 1979, que dispuso que «los procesos de separación conyugal, cualquiera que sea la forma de celebración del matrimonio, se sustanciarán y decidirán por los Jueces de Primera Instancia con arreglo a las normas de procedimiento establecidas en la LEC». Por tanto, los procesos de separación se rigen actualmente por el $\mathrm{CC}^{50}$ (en lo referente a su parte sustantiva) y la $\mathrm{LEC}^{51}$ (en lo relativo a la parte procesal). El resto de las causas (nulidad y disolución), aunque tendrán efectos civiles cuando sean conocidas por Tribunales eclesiásticos, no los producirán de manera automática, sino que se requerirá una homologación o control por parte de los Tribunales civiles, ex. artículo 954 LEC.

La situación actual es, por tanto, la siguiente: los españoles disponen del remedio jurídico de la separación civil, mientras que los católicos pueden escoger entre la civil y la canónica, sabiendo que la se-

\footnotetext{
${ }^{46}$ Aprecian ÁlVAREZ ALARCÓN, A., y BLANDINO GARRIDO, M. A. Eficacia civil de resoluciones matrimoniales eclesiásticas, en VV. AA. (Coord. por M. A. BLANDINO GARRIDO), Las crisis matrimoniales. Nulidad, separación y divorcio, Tirant lo Blanch, Valencia, 2010, pág. 667, que «una vez promulgada la Constitución Española, (...) se pasó del principio de confesionalidad que imperaba hasta entonces (...) a un Estado laico, regido por el principio de libertad religiosa de los ciudadanos, de suerte que la materia específica del matrimonio canónico y de los efectos derivados de las crisis matrimoniales fueron objeto de una nueva regulación, hasta el punto de que desde el 4 de diciembre de 1979, fecha del Instrumento ratificador del Acuerdo sobre Asuntos Jurídicos con la Santa Sede de 3 de enero de 1979, sólo se reconocían las declaraciones de nulidad de matrimonio canónico y las decisiones pontificias de matrimonio rato y no consumado, (...), cuando se declarasen ajustadas al Derecho del Estado».

${ }^{47}$ Entre España y la Santa Sede, ratificado el 4 de diciembre de 1979.

${ }^{48}$ No obstante, sí pueden reconocerse efectos aislados fundados en títulos legales diversos de la mera separación conyugal (por ejemplo, medidas relativas al régimen económico pactado entre los cónyuges).

${ }^{49}$ Esto mismo es descrito con detalle por SANCHO REBULLIDA, en Op. cit., pág. 19.

${ }^{50}$ Arts. 81 a 84 y 90 a 106 CC.

${ }^{51}$ Arts. 769 y ss. CC.
} 
gunda no producirá per se efectos civiles $^{52}$, por lo que incluso el propio $\mathrm{CIC}^{53}$ aconseja acudir a la jurisdicción civil si lo que se pretende es la generación de estos efectos. Hay autores que llegan a afirman que en España se presume una licencia tácita de los cónyuges para acudir directamente a la jurisdicción civil ${ }^{54}$ para obtener la separación del matrimonio canónico ${ }^{55}$.

Es importante señalar que estamos hablando de crisis conyugales de matrimonios válidos, no de matrimonios cuya nulidad es susceptible de ser declarada por los Tribunales civiles o eclesiásticos, debido a la concurrencia de vicios en el momento de prestar el consentimiento.

Existen diversas causas o "capítulos» de nulidad canónica, distintos de las causas de nulidad civil pero que, a fin de cuentas, coinciden con ésta última en que en todas ellas existe un grave vicio del consentimiento prestado a la hora de contraer matrimonio, o bien un impedimento legal para el cual no se ha pedido dispensa. No entramos a analizar este aspecto, puesto que no es el objeto del presente trabajo. Pero no queremos dejar de señalar que, en cualquiera de los dos tipos de nulidad -civil o canónica-, lo esencial es que el consentimiento no fue libre y verdaderamente prestado, por lo que el matrimonio no se celebró válidamente, a pesar de su posible apariencia de validez, y con independencia del tiempo transcurrido entre dicha celebración y la declaración de la nulidad.

\section{V. ¿ES EQUIPARABLE LA SEPARACIÓN CANÓNICA A LA SEPARACIÓN CIVIL DE HECHO?}

La consideración que, en el ámbito civil, se le otorga a una separación realizada conforme al Derecho Canónico, es la de separación de hecho ${ }^{56}$, a saber: "situación fáctica de cese de la convivencia conyu-

52 «No es posible obtener la eficacia civil de las sentencias eclesiásticas de separación. Así se estableció por el TC en la sentencia de 26 de enero de 1981 ». Vid. BLANDINO GARRIDO, M. A. La separación matrimonial, en VV. AA. (Coord. por M. A. BLANDINO GARRIDO), Las crisis matrimoniales. Nulidad, separación y divorcio, Tirant lo Blanch, Valencia, 2010, pág. 96. En la misma línea se pronuncia la Sentencia de la AP de Barcelona, Sección 18. ${ }^{\text {, de }} 20$ de marzo de 2007.

${ }^{53}$ Canon 1692.3 CIC.

${ }^{54}$ Vid. DE DIEGO LORA, C. «La eficacia en el orden civil de las resoluciones eclesiásticas en materia matrimonial», Ius Canonicum, 19, 37, 1979, pág. 207.

${ }^{55}$ FERRER ORTIZ, Op. cit., pág. 393.

${ }^{56}$ ESCRIVÁ-IVARS, Op. cit., págs. 261 y 262. 
gal, sin observar las formalidades legales de la separación judicial $»^{57}$. Es conveniente tener en cuenta que, para poder constatar una situación de separación de hecho, son necesarios tanto el corpus (separación física de los cónyuges o distanciamiento de la convivencia) como el animus (intencionalidad de la separación, al menos temporalmente, debido al cese de la affectio maritalis) ${ }^{58}$. Cuando, en el ámbito civil, se califica una situación como "de hecho", se pone de relieve la circunstancia de que, por falta del correspondiente refrendo legal o judicial, dicha situación carece de un reconocimiento jurídico pleno ${ }^{59}$.

Señala el Profesor LASARTE ÁLVAREZ que este tipo de separaciones de hecho ha sido potenciado por la reforma del Código Civil de 1981, en aras de una mayor privacidad de las crisis matrimonia$\operatorname{les}^{60}$, así como de la búsqueda de un menor coste ${ }^{61}$, por contraposición a los procesos judiciales. En palabras del Profesor FERNÁNDEZ GONZÁLEZ-REGUERAL, «tras la Ley de 7 de julio de 1981 se observa una mayor relevancia de la separación de hecho en nuestro ordenamiento, a la que se conceden efectos tan importantes como el de destruir la presunción de paternidad del artículo 116 CC e influir sobre la custodia de los hijos (arts. 156 y 159 CC), así como sobre la atribución de cargos tutelares (184 CC). Produce también efectos la separación de hecho en orden a la administración de los bienes gananciales (art. 1388 CC) y en la presunción que para el caso de quiebra o concurso de uno de los cónyuges está prevista en el artículo 1142 CC; además de la ya referida supresión de derechos en la sucesión intestada ${ }^{62}$. También tiene efectos sobre la recíproca obligación de alimentos entre cónyuges, que se determinará en función de las posibilidades económicas y necesidades de cada uno, así como sobre el cese de la obligación de convivencia.

Llegamos así, pues, a la interesante conclusión de que, si bien la separación canónica no carece explícitamente de efectos jurídicos en el ordenamiento civil, lo cierto es que sí puede generarlos a través de

${ }^{57}$ BLANDINO GARRIDO, Op. cit., pág. 100.

${ }^{58}$ Estos mismos requisitos fueron recalcados por la SAP de Zaragoza, de 21 de octubre de 1985.

${ }^{59}$ CASTILLA BAREA, M. "La separación», en YZQUIERDO TOLSADA, M., y CUENA CASAS, M. Tratado de Derecho de la Familia, Vol. II, Las Crisis Matrimoniales, Thomson Reuters, Pamplona, 2011, pág. 138.

${ }^{60}$ Cuanta menos trascendencia pública se de a la separación, mayor facilidad habrá de cara a una posible reconciliación de los cónyuges.

${ }^{61}$ LASARTE ÁLVAREZ, Op. cit., pág. 88.

${ }^{62}$ FERNANDEZ GONZÁLEZ-REGUERAL, M. A. "La separación de hecho conyugal y la legítima del cónyuge viudo», Actualidad Civil, n. 4, 1996, pág. 881. 
la consideración de esta situación como análoga a la de la separación de hecho.

El ordenamiento civil ha ido, pues, concretando poco a poco los efectos jurídicos de las separaciones de hecho ya que, aunque los cónyuges no busquen de manera directa la juridificación del cese de la convivencia, es evidente que el Derecho no puede permanecer ajeno ${ }^{63}$ a este tipo de decisiones, tan trascendentes para los derechos de terceros (hijos, acreedores, etc.), así como para los de los propios cónyuges, por cuya integridad debe velar el ordenamiento en el seno de cualquier crisis matrimonial. No se trata de situaciones ilícitas o ilegales, sino simplemente desarrolladas parcialmente al margen del cauce regulatorio que ofrece el ordenamiento. Es por ello que la mayoría de la doctrina califica la separación de hecho como un acto real $^{64}$, extrajurídico, que, sin embargo, sí es susceptible de provocar numerosas consecuencias jurídicas.

El derecho a la separación en el ámbito canónico tiene, como dice ESCRIVÁ-IVARS ${ }^{65}$, una naturaleza privada, por lo que los cónyuges pueden ejercitarlo sin necesidad alguna de la autoridad pública, constituyendo un verdadero estado jurídico de separación, tan legítimo como la separación judicial o administrativa. Eso sí, a diferencia del orden civil, en el canónico se requiere que las causas que excusen del deber de convivencia sean ciertas y graves.

Cabe la posibilidad de que, al separarse de hecho y de manera convencional (con acuerdo de ambos cónyuges) ${ }^{66}$, éstos concreten su decisión en un pacto conyugal, instrumentado -señala LASARTE- en numerosas ocasiones en escritura pública ante Notario ${ }^{67}$. El contenido de dichos acuerdos suele englobar extremos como el uso de la vivienda familiar, ciertas decisiones sobre el régimen económico del matrimonio, pactos relativos a la obligación de alimentos... Desde la Reforma del Código Civil de $1981^{68}$ se reconoce la plena validez de ese tipo de pactos $^{69}$, teoría refrendada en varias ocasiones por la jurisprudencia, con el único límite de que no atenten contra el orden público, ni afecten a cuestiones indisponibles (estableciendo, por ejemplo,

${ }^{63}$ De la misma opinión es LORENZO CRUZ, en Op. cit., pág. 507.

${ }^{64}$ LÓPEZ-MÚÑIZ CRIADO, Op. cit., pág. 184.

${ }^{65}$ ESCRIVÁ-IVARS, Op. cit., pág. 259.

${ }^{66} \mathrm{Vid}$. Disposición Final 18. ${ }^{\mathrm{a}}$ de la LJV.

${ }^{67}$ LASARTE ÁLVAREZ, Op. cit., pág. 98.

${ }^{68}$ Señala BLANDINO GARRIDO, en Op. cit., pág. 106, que en la Ley 30/1981, de 7 de julio, "se reconoce un auténtico contractualismo en el ámbito del derecho familiar». Vid. artículos 81.1 y 90 de dicha Ley.

${ }^{69}$ Vid. STS de 25 de junio de 1987, 26 de enero de 1993 y 19 de diciembre de 1997. 
medidas relativas a los hijos menores de edad), ni vulneren el principio de igualdad entre cónyuges.

\section{CONCLUSIONES}

I. En España existe, de entre los varios sistemas matrimoniales posibles, uno plural y electivo, que se ha visto ampliado en su espectro de selección gracias a la incorporación, en 2015, de las confesiones con notorio arraigo en nuestro país. De modo que no solo el matrimonio civil sino también los celebrados en forma religiosa pueden tener efectos civiles, siempre que se cumplan las prescripciones del modificado artículo $60 \mathrm{CC}$. Es interesante conocer este panorama, ya que en función del tipo de matrimonio del que hablemos, la regulación de las crisis matrimoniales será distinta.

II. La separación civil surge como figura autónoma en el ordenamiento con la inclusión del divorcio, por mor de la reforma legislativa de 1981. En esa fecha, el sistema de matrimonio único religioso fue sustituido por el de matrimonio civil obligatorio con posibilidad de celebración según las confesiones religiosas reconocidas en ese momento. La separación solo podía tener lugar en caso de concurrir unas causas tasadas, y la ley distinguía entre el cónyuge culpable y el inocente en las situaciones de crisis conyugal.

III. La reforma operada por la Ley 15/2005, pretendió poner fin al divorcio y la separación causalistas. A partir de su entrada en vigor, fue reconocida la posibilidad de la separación judicial a solicitud, incluso, de uno solo de los cónyuges. Si no, siempre existía la posibilidad de la separación de hecho. No obstante, en sede canónica, pervive el requisito de la causalidad para acceder a la separación. Dado que en nuestro ordenamiento pueden concurrir las separaciones civil y canónica, consideramos que esta última tendría, si quisiéramos hablar de una generación directa de efectos en el orden civil, la consideración de una separación de hecho, a la cual -por cierto- se le ha dado un creciente reconocimiento en los últimos años.

IV. En cualquier caso, tanto la separación civil como la canónica deben distinguirse de la nulidad -civil o canónica-, que hace alusión a la falta de vínculo por una ausencia de consentimiento matrimonial válido, puesto que en la separa- 
ANálisis de la Separación Canónica y Civil en el Sistema...

ción el vínculo conyugal permanece inalterado a pesar del distanciamiento entre los cónyuges.

V. Otra de las novedades de la Ley 15/2015 ha sido la desjudicializacion de diversas materias, -entre las cuales se encuentra la separación matrimonial-, atribuyendo su conocimiento a otros operadores jurídicos distintos del Juez, de modo que el acceso a la separación judicial es más rápido y sencillo en la vigente legislación.

\section{BIBLIOGRAFÍA}

ÁLVAREZ ALARCÓN, A., y BLANDINO GARRIDO, M. A., «Eficacia civil de resoluciones matrimoniales eclesiásticas», en VV. AA., (Coord. por M. A. BLANDINO GARRIDO), Las crisis matrimoniales. Nulidad, separación y divorcio, Tirant lo Blanch, Valencia, 2010, págs. 663-694.

ARISTÓTELES, Ética a Nicómaco, Mestas, Madrid, 2006.

BERCOVITZ RODRÍGUEZ-CANO, R., «La ejecución de las sentencias eclesiásticas de separación matrimonial por la jurisdicción civil después de la Constitución: comentario a la STC de 26 de enero de 1981», Revista española de Derecho Constitucional, 1, 3, 1981, págs. 123-168.

BLANDINO GARRIDO, M. A., "La separación matrimonial», en VV. AA., (Coord. por M. A. BLANDINO GARRIDO), Las crisis matrimoniales. Nulidad, separación y divorcio, Tirant lo Blanch, Valencia, 2010, págs. 95-128.

CAÑAMARES ARRIBAS, S., «El sistema matrimonial español», en VV. AA., Coord. por JUSDADO RUIZ-CAPILLAS, M. A., Derecho Matrimonial Canónico y Eclesiástico del Estado, Colex, Madrid, 2007, pág. 255-270.

CASTILLA BAREA, M., "La separación», en YZQUIERDO TOLSADA, M., y CUENA CASAS, M., Tratado de Derecho de la Familia, Vol. II, Las Crisis Matrimoniales, Thomson Reuters, Pamplona, 2011, págs. 133-223.

DE DIEGO LORA, C., "La eficacia en el orden civil de las resoluciones eclesiásticas en materia matrimonial», Ius Canonicum, 19, 37, 1979, págs. 155-228. 
DÍEZ-PICAZO, L. y GULLÓN, A., Sistema de Derecho Civil. Derecho de Familia. Derecho de Sucesiones, Vol. IV, Tecnos, Madrid, 2008.

D’ORS, A., Derecho Privado Romano, Eunsa, Pamplona, 1991.

ESCRIVÁ-IVARS, J., «Separación conyugal y mediación», Ius Canonicum, 61, 81, 2001, pág. 247-292.

FERNÁNDEZ GONZÁLEZ-REGUERAL, M. A., "La separación de hecho conyugal y la legítima del cónyuge viudo», Actualidad Civil, n. ${ }^{\circ}$ 4, 1996, pág. 879-894.

FERRER ORTIZ, J., «La eficacia civil del matrimonio canónico y de las decisiones eclesiásticas en el Derecho español», Ius et Praxis, 14, 2, 2008, págs. 373-406.

GARCÍA GÁRATE, A., El matrimonio canónico en su dimensión sustantiva y procesal, Dykinson, Madrid, 2007.

LASARTE ÁlVAREZ, C., Derecho de Familia. Principios de Derecho Civil VI, Marcial Pons, Madrid, 2010.

LIPKA, W., «La separación matrimonial canónica: una propuesta de recuperación», Ius Canonicum, 41, 82, 2001, págs. 501-548.

LÓPEZ-MÚÑIZ CRIADO, C., Separación, en VV. AA., Coord. por O'CALLAGHAN, X., Matrimonio: nulidad canónica y civil, separación y divorcio, Editorial Centro de Estudios Ramón Areces, Madrid, 2007, págs. 179-203.

LORENZO CRUZ, A., "La separación matrimonial de hecho», Anuario de la Facultad de Derecho, n. ${ }^{\circ}$ 3, 1984-1985, págs. 505-520.

MARTÍNEZ LUNA, M. C., «Influencia de la separación de hecho en el régimen de gananciales», Revista Jurídica de Catalunya, n. ${ }^{\circ}$ 93, 1994, pág. 1077-1080.

MARTÍNEZ SAGASTI, A. M., «Procedimientos jurídicos para la separación conyugal», Ius Canonicum, 17, 34, 1977, pág. 105-171.

NAVARRO-VALLS, R., «La posición jurídica del matrimonio canónico en la Ley de 7 de julio de 1981», Revista de Derecho Privado, 1982, n. ${ }^{\circ} 66$, págs. 665-709.

PEÑA GARCÍA, C., El matrimonio. Derecho y praxis de la Iglesia, Universidad Pontificia Comillas, Bilbao, 2004.

PERALES AGUSTÍ, M., «Los impedimentos matrimoniales», en VV. AA., Coord. por JUSDADO, M., Derecho Matrimonial Canónico y Eclesiástico del Estado, 2. ${ }^{a}$ edición, Colex, Madrid, 2007, págs. 65-100. 
ROMERO COLOMA, A. M., «La esquizofrenia como causa de separación matrimonial en el Ordenamiento Jurídico Civil español», Revista Crítica de Derecho Inmobiliario, 76, 658, 2000, págs. 1477-1490.

SANCHO REBULLIDA, F., «El matrimonio canónico en el sistema matrimonial español», Ius Canonicum, 20, 40, 1980, págs. 15-38.

SATORRAS FIORETTI, R. M., «Los matrimonios religiosos con eficacia civil», en VV. AA., Coord. por VILLAGRASA ALCAIDE, C., Derecho de Familia, Bosch, Barcelona, 2011, págs. 53-145.

TEJERO, E., «La sacramentalidad del matrimonio en la historia del pensamiento cristiano», Ius Canonicum, 14, 27, 1974, págs. 12-35.

VV.AA., «El momento crítico de los matrimonios religiosos», en YZQUIERDO TOLSADA, M., y CUENA CASAS, M., Tratado de Derecho de la Familia, Vol. II, Las Crisis Matrimoniales, Thomson Reuters, Pamplona, 2011, págs. 837-934.

\section{VIII. ÍNDICE DE RESOLUCIONES CITADAS}

STS de 3 de enero de 1983.

STS de 25 de noviembre de 1985.

STS de 25 de junio de 1987.

STS de 19 de diciembre de 1997.

SAP Zaragoza de 21 de octubre de 1985.

SAP Palencia de 25 de abril de 1994.

SAP Barcelona de 20 de marzo de 2007. 
